\title{
Phosphatidylinositol 4,5-bisphosphate
}

National Cancer Institute

\section{Source}

National Cancer Institute. Phosphatidylinositol4,5-bisphosphate. NCI Thesaurus. Code C1192.

A phospholipid that is a component of the plasma membrane with signal transduction inducing activity. Phosphatidylinositol 4,5-bisphosphate (PIP2) is an intermediate that can be converted into either the second messenger signaling molecules, inositol 1,4,5trisphosphate (IP3) and diacylglycerol (DAG), or phosphatidylinositol $(3,4,5)$-trisphosphate (Ptdlns(3,4,5)P3; PIP3). Both PIP2 and PIP3 can act as docking phospholipids, which recruit signaling proteins to the plasma membrane and promotes the activation of several signaling cascades. 